\title{
Investigating changes in basal conditions of Variegated Glacier prior to and during its 1982-1983 surge
}

\author{
M. Jay-Allemand ${ }^{1}$, F. Gillet-Chaulet ${ }^{1}$, O. Gagliardini ${ }^{1,2}$, and M. Nodet $^{3}$ \\ ${ }^{1}$ Laboratoire de Glaciologie et de Géophysique de l'Environnement (LGGE), UMR5183, CNRS/UJF, \\ Grenoble, BP 96, 38402 Saint Martin d'Hères Cedex, France \\ ${ }^{2}$ Institut Universitaire de France (IUF), 103, bd Saint-Michel, 75005 Paris, France \\ ${ }^{3}$ UJF Grenoble, INRIA, Laboratoire Jean Kuntzmann (LJK), BP 53, 38041 Grenoble Cedex 09, France \\ Received: 22 April 2011 - Published in The Cryosphere Discuss.: 12 May 2011 \\ Revised: 29 July 2011 - Accepted: 19 August 2011 - Published: 23 August 2011
}

\begin{abstract}
Variegated Glacier (Alaska) is known to surge periodically after a sufficient amount of cumulative mass balance is reached, but this observation is difficult to link with changes in the basal conditions. Here, using a 10-yr dataset, consisting of surface topography and surface velocity observations along a flow line for 25 dates, we have reconstructed the evolution of the basal conditions prior to and during the 1982-1983 surge. The model solves the full-Stokes problem along the central flow line using the finite element method. For the 25 dates of the dataset, the basal friction parameter distribution is inferred using the inverse method proposed by Arthern and Gudmundsson (2010). This method is here slightly modified by incorporating a regularisation term in the cost function to avoid short wavelength changes in the friction parameter. Our results indicate that dramatic changes in the basal conditions occurred between 1973 to 1983. Prior to the surge, periodic changes can be observed between winter and summer, with a regular increase of the sliding from 1973 to 1982 . During the surge, the basal friction decreased dramatically and an area of very low friction moved from the upper part of the glacier to its terminus. Using a more complex friction law, these changes in basal sliding are then interpreted in terms of basal water pressure. Our results support that dramatic changes took place in the subglacial drainage system of Variegated Glacier, moving from a relatively efficient drainage system prior to the surge to an inefficient one during the surge. By reconstructing the water pressure evolution at the base of the glacier it is possible to propose a scenario for the hydrological history leading to the occurrence of a surge.
\end{abstract}

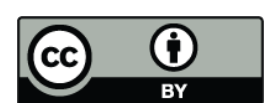

Correspondence to: O. Gagliardini (gagliar@lgge.obs.ujf-grenoble.fr)

\section{Introduction}

Variegated Glacier is a temperate glacier located in the coastal St Elias Mountains in Alaska (USA). It is approximately $20 \mathrm{~km}$ long and $1 \mathrm{~km}$ wide, with ice flowing from the altitude of $2000 \mathrm{~m}$ a.s.l. down to the sea. Due to its surging behaviour, Variegated Glacier has been intensively studied these last decades (Bindschadler et al., 1977; Bindschadler, 1982; Kamb et al., 1985; Raymond and Harrison, 1988; Eisen et al., 2001, 2005). Since the first listed surge of 1905-1906, Variegated Glacier has undergone 7 other surges until the last observed in 2003-2004 (Harrison et al., 2008). From the well-studied 1982-1983 surge, it seems that Variegated Glacier is characterised by a two-phase surge, each phase with a reasonably distinct termination separated by one year (Eisen et al., 2005). Velocity and elevation changes were more marked in the upper glacier during the first phase of the 1982-1983 surge, whereas during the second phase, the surge propagated progressively down into the lower glacier. The highest velocity of the whole surge were observed during the second phase on the lower glacier (Kamb et al., 1985). One other characteristic is the seasonal timing of Variegated surges, with an onset in late autumn or winter and termination in late spring or early summer.

As shown by Eisen et al. (2001), the duration of the quiescent phase in between two surges is very well correlated with the total cumulative mass balance at a point located at the altitude of $1500 \mathrm{~m}$ in the accumulation area. Variegated Glacier is found to surge each time the ice-equivalent cumulative balance at this particular point reaches the threshold value of $43.5 \pm 1.2 \mathrm{~m}$. This relation is not fulfilled for the 2003-2004 surge, for which the cumulative mass balance was only half of that required for previous surges (Harrison et al., 2008). As anticipated by Eisen et al. (2005), this loss of correlation might be explained by the early termination of the one-phase

Published by Copernicus Publications on behalf of the European Geosciences Union. 
1995 surge and its unusual post-surge surface topography corresponding to a relatively small mass transfer from the upper part to the lower part of the glacier. Because the 20032004 was a normal two-phase surge, Harrison et al. (2008) have predicted that the mass balance correlation will hold for the next surge. Nevertheless, the causality of this mass balance surface observation has not yet been linked to the basal processes controlling the surge.

Surges of temperate glaciers are initiated by a change in the basal hydrological system, which moves from a discrete efficient system with low water pressure and high water discharge to a distributed inefficient system with high water pressure (e.g. Raymond, 1987). A discrete efficient system is usually formed by a few large channels and its influence on the ice flow is relatively low, whereas an inefficient system consists of small linked cavities strongly influencing the basal velocity (Kamb, 1987). As explained by Eisen et al. (2005), there is a seasonal pattern of surge initiations and terminations. Variegated surge initiations are certainly governed by a change in the glacier's geometry, during the quiescent phase, which affects the internal drainage system. When a threshold amount of surface elevation and/or surface slope changes are reached, the discrete system closes at the end of the melting season when the amount of water is insufficient to keep it open. Then, subsequent rain or meltwater from the surface, even in small volume, will progressively contribute to increase the basal water pressure, finally leading to the glacier surge. The following spring, when the amount of water is again sufficient, the discrete efficient system opens again and the surge stops (Harrison and Post, 2003; Lingle and Fatland, 2003). Note that this interpretation is consistent with the observed timing of Variegated surges, which started during the winter and end during the summer.

During the 1982-1983 surge, short-term variations (hours to days) of ice velocity, water pressure and outflow stream at the glacier terminus have been observed. These observations indicate the predominant contribution of basal sliding during the surge phase. Measurements of the internal deformation in a borehole during the surge show that $95 \%$ of the surface velocity is due to sliding (Kamb et al., 1985). Velocities as high as $50 \mathrm{~m} \mathrm{day}^{-1}$ were measured during the second phase of the 1982-1983 surge. Simultaneous records of water pressure from borehole measurements indicate the strong correlation between water pressure and velocity. Pulses in surge movement do indeed correspond to peaks in pressure. Conversely, the increase of the outflow stream at the terminus is closely correlated with a rapid slowdown of the glacier (Kamb et al., 1985). This last observation indicates that a large amount of water is stored in subglacial cavities, inducing an increase in water pressure and a consequent increase in ice sliding velocities. But when a threshold pressure is reached, the subglacial water storage purges, leading to flooding at the terminus outflow and to a slowdown of the ice sliding.

In this paper, we propose to use the very well documented period from 1973 to 1983 to reconstruct the history of the basal conditions below Variegated Glacier using a full-Stokes model. The available dataset for Variegated is presented and discussed in the first Section. The direct full-Stokes flow line model is presented in the second Section. The associated inverse model (Arthern and Gudmundsson, 2010) and its extension is presented in the third Section. In the fourth Section, the inverse model is used to infer the basal friction distribution along the flow line at each measurement date. In the fifth Section, following the idea proposed by Flowers et al. (2011), changes in the basal friction parameter are interpreted in terms of changes in basal water pressure through the use of the water pressure dependent friction law proposed by Schoof (2005) and Gagliardini et al. (2007). Finally, using the basal friction parameter distributions inferred from the inverse method, a transient simulation is run over the 10-yr data period to compare modelled and observed surface geometry evolutions.

\section{Description of the datasets}

Extensive measurements of the surface topography and surface velocities were carried out during the 1973-1983 decade (Bindschadler et al., 1977; Kamb et al., 1985; Raymond and Harrison, 1988). This measurement period covers the last part of the quiescent phase which follows the 1964-1965 surge and includes the 1982-1983 surge. During this period, surface elevation and horizontal surface velocity were measured at 25 different dates, twice a year prior to the surge and 8 times during the $2 \mathrm{yr}$ of the surge. At each date, the dataset is composed of the horizontal surface velocity and the surface elevation every $250 \mathrm{~m}$ along the $20 \mathrm{~km}$ of the central flow line. Most of the datasets are incomplete, mainly in the upper and lower parts, but also where the glacier was too crevassed to be accessible. Few attempts have been made to reconstruct the basal condition history below Variegated Glacier from these datasets. Raymond and Harrison (1988), using a very simple flow line model, determined that basal sliding increased from 1973 to 1981 and concluded that by 1981, basal sliding might be $50 \%$ or more of the total surface velocity in the upper part of the glacier. Again with a relatively simple hydrological model, Eisen et al. (2005) showed that the flux required to keep the efficient drainage system open is very sensitive to the basal shear stress. Combining the model and the observations, they determined a critical basal shear stress along the flow line which initiates a surge.

\section{Direct diagnostic model}

\subsection{Field equation}

Available data for Variegated Glacier are limited to the central flow line of the glacier. Therefore, the modelling is limited to a two-dimensional flow line geometry, delimited by the bedrock $b(x)$ and the upper surface $z_{\mathrm{s}}(x)$. We further 
assume a Cartesian coordinate system such that $x$ is the horizontal direction and $z$ the up-oriented vertical one. For a given geometry, the ice flow is governed by the Stokes equations, i.e. the mass and momentum conservation equations in which the acceleration terms are neglected. The Stokes equations are written:

$\operatorname{div} \boldsymbol{u}=0, \quad b \leq z \leq z_{\mathrm{s}}$,

$\operatorname{div} \boldsymbol{\sigma}+\rho \boldsymbol{g}+\boldsymbol{f}_{1}=0, \quad b \leq z \leq z_{\mathrm{s}}$,

Here $\boldsymbol{u}=\left(u_{x}, 0, u_{z}\right)$ is the velocity vector, $\boldsymbol{\sigma}=\boldsymbol{\tau}-p \boldsymbol{I}$ is the Cauchy stress tensor and $p$ the isotropic pressure, $\rho$ the ice density and $\boldsymbol{g}=(0,0,-g)$ the gravity vector. The body force $f_{1}$ is added in the flow line model to account for the friction arising on the lateral side of a real glacier. To this end, the concept of shape factor (Nye, 1965) is here extended to the full-Stokes formulation by defining the body force $f_{1}$ as

$\boldsymbol{f}_{1}=-\rho \boldsymbol{g} \cdot \boldsymbol{t}(1-f) \boldsymbol{t}$,

where the shape factor $f=f(x)$ is a scalar function of the transversal shape of the glacier and $\boldsymbol{t}$ is the unit vector tangent to the upper surface. As shown by this equation, the concept of shape factor adds a resistive body force tangent to the upper surface. When $f=1$, the limit case of an infinitely large glacier is obtained, whereas small $f$ stands for narrow and/or deep transverse sections.

Here, we evaluate $f(x)$ by assuming that the transverse shape of the bedrock is a parabola of the form $\tilde{b}(x, y)=$ $b(x)+a(x) \cdot y^{2}$, where the parabola coefficient $a(x)$ is constant in time and estimated from the thickness and width measurements performed in 1973 (Raymond and Harrison, 1988). This approach accounts for variations with time of the shape factor induced by changes in ice thickness.

Following the approach of Nye (1965), the relation between the shape factor and the ice thickness in the central flow line is inferred from three-dimensional full-Stokes simulations of an infinitely long glacier flowing over a parabolatype bedrock using different values of the friction parameter. All these three-dimensional simulations (not shown here), are well reproduced with a two-dimensional flow line model using the following empirical estimate of the shape factor:

$f=\frac{2}{\pi} \arctan \left(\frac{0.8146}{\sqrt{a \cdot h}}\right)$,

where $h(x)=z_{\mathrm{s}}(x)-b(x)$ is the ice thickness. Figure 1 shows the evolution of the shape factor $f(x)$ along the flow line for the 1973 geometry.

The ice rheology is described through a power-type flow law, known as Glen's law in glaciology, linking the strainrate tensor $\dot{\boldsymbol{\varepsilon}}$ to the deviatoric stress tensor $\boldsymbol{\tau}$ such that:

$\dot{\boldsymbol{\varepsilon}}=A \tau_{e}^{n-1} \boldsymbol{\tau}$,

where $\tau_{e}^{2}=\tau_{i j} \tau_{i j} / 2$ is the square of the second invariant of the deviatoric stress and $A$ a rheological parameter, which

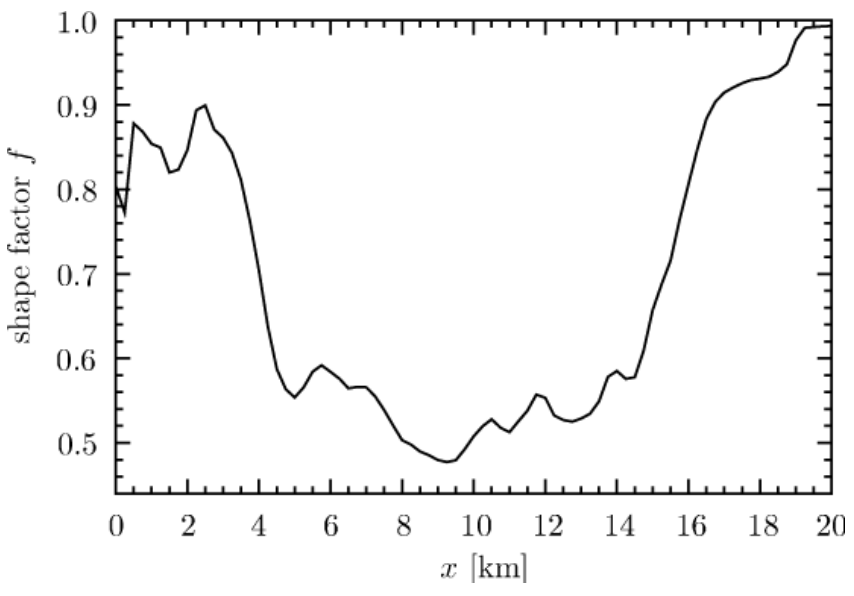

Fig. 1. Evolution of the shape factor $f$ along the central flow line for the 1973 surface topography.

depends on the ice temperature via an Arrhenius law. Since Variegated Glacier is temperate, the constant value $A=$ $100 \mathrm{MPa}^{-3} \mathrm{a}^{-1}$ is adopted (close to the ones proposed in Cuffey and Paterson, 2010).

\subsection{Boundary conditions}

The upper surface $\Gamma_{\mathrm{s}}$, i.e. $z=z_{\mathrm{s}}$, is a stress-free surface and the following Neumann-type boundary condition applies:

$\boldsymbol{\sigma} \cdot \boldsymbol{n}=0$ for $z=z_{\mathrm{s}}$.

At the bedrock interface $\Gamma_{\mathrm{b}}$, i.e. $z=b$, zero basal melting is assumed $(\boldsymbol{u} \cdot \boldsymbol{n}=0)$ as well as a linear friction law (Robin type boundary condition). This linear friction law relates the basal drag $\tau_{n t}$ to the sliding velocity $u_{t}$ such that:

$\tau_{n t}=\left.\boldsymbol{t} \cdot(\boldsymbol{\sigma} \cdot \boldsymbol{n})\right|_{b}=-\beta \boldsymbol{u} \cdot \boldsymbol{t}=-\beta u_{t}$ for $z=b$,

where $\boldsymbol{n}$ and $\boldsymbol{t}$ are the normal and tangent unit vectors to the bedrock surface, and $\beta \geq 0$ is the basal friction parameter.

All these equations are solved using the finite element method with the code Elmer/Ice. More details on the numerics can be found in Gagliardini et al. (2007) and Gagliardini and Zwinger (2008).

\section{The inverse problem}

Determining the optimal basal conditions from the glacier topography and the surface velocities is an inverse problem. Recently, three methods have been proposed to solve this particular inverse problem using a full-Stokes direct model. The first one, is a Bayesian method developed by Gudmundsson and Raymond (2008) and further applied to the Rutford ice stream (West Antarctica, Raymond Pralong and Gudmundsson, 2011). Note that for this application to real 
data, both basal friction and bedrock topography were inferred by inverting surface data. The two others, which belong in the class of the the variational methods, are a control method using the adjoint model of the linear Stokes equations (Morlighem et al., 2010) and a Robin inverse method (Arthern and Gudmundsson, 2010).

These two variational methods rely on the minimisation of a cost function that measures the mismatch between the model and the observations. In each case, the gradient of the cost function with respect to the basal drag coefficient is obtained analytically assuming a linear flow law and a linear sliding law. Theoretically, these results could be extended to non-linear laws but this would require further analytical and numerical developments. In their applications, Morlighem et al. (2010) and Arthern and Gudmundsson (2010) show that even by using the gradient derived in the linear case, it is possible to minimise the cost function with non-linear laws, but this could fail for some applications (Goldberg and Sergienko, 2011). These two methods should lead to very similar solutions for the basal drag coefficient and both have advantages and drawbacks. The control method needs the derivation of the adjoint model but it is easy to modify the cost function to take into account the error on the observed velocities. The Robin inverse method can be easily implemented using the direct model only, but does not integrate the observation errors in the cost function.

In this paper we present results obtained with the Robin inverse method (Arthern and Gudmundsson, 2010), extended with a regularisation term. The inverse method has been implemented in the finite element code Elmer/Ice. To our knowledge this is the first application of this method to real data in glaciology.

\subsection{Robin method}

The inverse problem is, for each dataset (surface geometry and velocities), to determine the basal friction parameter $\beta$ that gives the smallest mismatch between observed and modelled surface velocities.

We use the inverse Robin method adapted to glaciology by Arthern and Gudmundsson (2010). The method consists of solving alternately the Neumann-type problem defined by Eqs. $(1,2)$ and the surface boundary conditions (Eq. 6), and the associated Dirichlet-type problem defined by the same equations excepted that the Neumann upper-surface condition (Eq. 6) is replaced by a Dirichlet condition, such that:

$u\left(z_{\mathrm{s}}\right)=u^{\mathrm{obs}}$,

where $u\left(z_{\mathrm{s}}\right)$ and $u^{\mathrm{obs}}$ are the model and observed surface horizontal velocities, respectively. This condition is enforced for each location where a surface velocity was measured. The natural Neumann condition is imposed in the vertical direction and where no observation is available.
The cost function that expresses the mismatch between the solution of the two models is given by

$J_{o}=\int_{\Gamma_{\mathrm{s}}}\left(\boldsymbol{u}^{\mathrm{N}}-\boldsymbol{u}^{\mathrm{D}}\right) \cdot\left(\boldsymbol{\sigma}^{\mathrm{N}}-\boldsymbol{\sigma}^{\mathrm{D}}\right) \cdot \boldsymbol{n} \mathrm{d} \Gamma$,

where superscripts " $\mathrm{N}$ " and "D" refer to the Neumann and Dirichlet problem solutions, respectively, and $\Gamma_{\mathrm{s}}$ denotes the upper surface of the glacier.

The Gâteaux derivative of the cost function $J_{o}$ with respect to the friction parameter $\beta$ for a perturbation $\beta^{\prime}$ is given by (Arthern and Gudmundsson, 2010):

$d_{\beta} J_{o}=\int_{\Gamma_{\mathrm{b}}} \beta^{\prime}\left(\left|\boldsymbol{u}^{\mathrm{D}}\right|^{2}-\left|\boldsymbol{u}^{\mathrm{N}}\right|^{2}\right) \mathrm{d} \Gamma$,

where the symbol |.| defines the norm of the velocity vector.

In this paper, to avoid unphysical negative values of the friction parameter, $\beta$ is expressed as

$\beta=10^{\alpha}$.

The optimisation is now done with respect to $\alpha$ and the Gâteaux derivative of $J_{o}$ with respect to $\alpha$ is obtained as follows:

$\mathrm{d}_{\alpha} J_{o}=\mathrm{d}_{\beta} J_{o} \frac{\mathrm{d} \beta}{\mathrm{d} \alpha}=\int_{\Gamma_{\mathrm{b}}} \alpha^{\prime}\left(\left|\boldsymbol{u}^{\mathrm{D}}\right|^{2}-\left|\boldsymbol{u}^{\mathrm{N}}\right|^{2}\right) 10^{\alpha} \ln (10) \mathrm{d} \Gamma$.

In the presence of noise in the observed velocities, the method can lead to spurious small wavelength oscillations of the inferred friction parameter. Arthern and Gudmundsson (2010) suggest terminating the minimisation when the cost function starts to stagnate at a certain level. Furthermore, the authors show that this is in agreement with a heuristic stopping criterion based on the observation errors. One drawback of this approach is that on a glacier, the magnitude of the velocities and the observation errors could vary strongly from one place to another, but also from one dataset to another, so that the stopping criterion should be different for each area and each dataset. Here, an additional Tikhonov regularisation term that penalises the small wavelength oscillations of the friction parameter $\beta$, taken as

$J_{\text {reg }}=\int_{\Gamma_{\mathrm{b}}}\left(\frac{\partial \alpha}{\partial x}\right)^{2} \mathrm{~d} \Gamma$,

is added to the cost function $J_{o}$. The total cost function is now

$J_{\mathrm{tot}}=J_{o}+\frac{1}{2} \lambda \bar{u}^{\mathrm{obs}} J_{\mathrm{reg}}$,

where $\bar{u}^{\text {obs }}$ is the mean value of the observed surface velocities and $\lambda$ is a weighting parameter used to adjust the influence of the added regularisation with respect to the initial cost function. The term $\bar{u}^{\text {obs }}$ takes into account the large changes in velocity observed along the $10-\mathrm{yr}$ dataset and allows us to use a unique value of the regularisation parameter $\lambda$ for all the datasets. Regularisation is classical in data 
assimilation: the minimisation of $J_{o}$ alone is an ill-posed problem, and the addition of a regularisation term ensures existence of a global minimum. If $\lambda$ is large enough, the problem becomes well-posed, with a unique minimum, and therefore the minimisation algorithm shows improved convergence properties. The form of the additional term ensures that the optimal $\beta$ is smooth. The effect of this regularisation term and the sensitivity of the $\beta$ distribution to $\lambda$ is discussed in Sect. 5.

The minimisation of the cost function $J_{\text {tot }}$ with respect to $\beta$ is done using the limited memory quasi-Newton routine M1QN3 (Gilbert and Lemaréchal, 1989) implemented in Elmer/Ice in reverse communication. In Newton's algorithm, the descent direction is a function of both the gradient and the Hessian of the cost function. Quasi-Newton's method is a widely-used variant of Newton's method which does not require to compute the Hessian but uses approximations instead, which are computed and improved throughout the iterations. This method has a convergence speed that is better than a fixed-step gradient method as presented in Arthern and Gudmundsson (2010). The cost function decreases quickly during the first 10 to 20 iterations then start to stagnate has shown by Arthern and Gudmundsson (2010). As the gradient used here is only an approximation of the true gradient for a non linear rheology, the iterative algorithm is usually stopped when the cost function cannot be decreased anymore in the descent direction, typically after 50 to 100 iterations.

\subsection{Technical aspects}

The Stokes equations and the Robin problem are solved using the finite element code Elmer/Ice. For each date, a regular mesh is constructed using 80 horizontal times 20 vertical layers of quadrangle elements, between the bedrock and upper surface. For ice-free areas, a minimal thickness of $3 \mathrm{~m}$ is imposed to avoid zero volume elements. Each of the 25 datasets is composed of the surface elevation and the horizontal surface velocity at 81 points regularly spaced every $250 \mathrm{~m}$ along the $20 \mathrm{~km}$ of the glacier length. Topographic measurements are representative of a given date whereas velocity measurements refer to the period in-between two measurement dates (Raymond and Harrison, 1988). For the quiescent period, the same surface topography is used for the summer and for the following winter. For the surge, because of the fast changing topography, for a given velocity measurement, the surface topography is taken as the time-weighted average of the two surface topographies corresponding to the surface velocity measurement dates. To construct the 25 geometries corresponding to the 25 datasets, the surface elevation must be defined along the whole glacier. Where surface topography measurements are missing, the elevation is estimated from the other datasets using a linear adjustment to fulfil the current surface elevation continuity. For the velocity, the mesh is constructed so that point measurements and mesh nodes coincide. When solving the Dirichlet problem, measured ve- locities are imposed only where measurements are available and no interpolation is used to complete missing data. We verified that a finer mesh does not change significantly the results of the inversion of the friction parameter.

\section{Inversion of the basal friction parameter}

\subsection{Influence of the regularisation term}

We used the most complete summer 1978 dataset to assess the influence of the regularisation term on the results. The inferred friction parameter $\beta$ and the associated surface and sliding velocities obtained for different values of the regularisation parameter $\lambda$ are shown in Fig. 2. The influence of $\lambda$ is directly observable in this figure. When $\lambda$ increases, the inferred friction parameter distribution gets smoother, but mean values over the glacier length of $\beta$ are very similar for all the values of $\lambda$. The relative mean error between observed and modelled velocities increases from 4.9 to $9.1 \%$ when $\lambda$ is increased from 0 to $10^{6}$. The difference between modelled and observed surface velocities remains small, but the short wavelength oscillations of the observed velocities are less well resolved when the regularisation term increases. The corresponding sliding velocities, depicted in Fig. 2c, are also smoothed when $\lambda$ is increased, but the gap between the different sliding velocity distributions is much larger than for the surface velocities. The comparison between surface and basal velocities shows that all these small wavelength oscillations arising at the base have almost no visible influence at the glacier surface.

The oscillations of the $\beta$ parameter in Fig. 2a are certainly partly physically created, as we expect that high and low friction areas may alternate at the base of Variegated glacier, but they are also certainly induced by errors on the measured velocities and on the model itself (mainly the flow line assumption and errors on the measured surface and bedrock topographies).

Therefore, a difficult task is to choose an optimal regularisation parameter $\lambda$, which will conduct to an optimal balance between the fit of the observed velocities and the smoothness of the inferred solution. As can be seen in Fig. 2b, the inferred velocities lie all in the error bar of the measured velocity (Raymond and Harrison, 1988), excepted that ones inferred for a penalisation larger than $10^{6}$. A first criteria is then to choose $\lambda<10^{6}$. An other possibility to estimate the optimal regularisation parameter $\lambda$ is the L-curve analysis (Hansen, 2001). The L-curve method uses the log$\log$ plot of the norm of the regularised solution $J_{\text {reg }}$ given by Eq. (13) versus the norm of the initial cost function $J_{o}$ (Eq. 9) to choose the optimal regularisation parameter. Theoretically, the L-curve should present a corner which allows to objectively estimate the optimal regularisation parameter $\lambda$. As shown in Fig. 3, for a non-linear model applied to real data, the L-curve analysis is not straightforward. The 


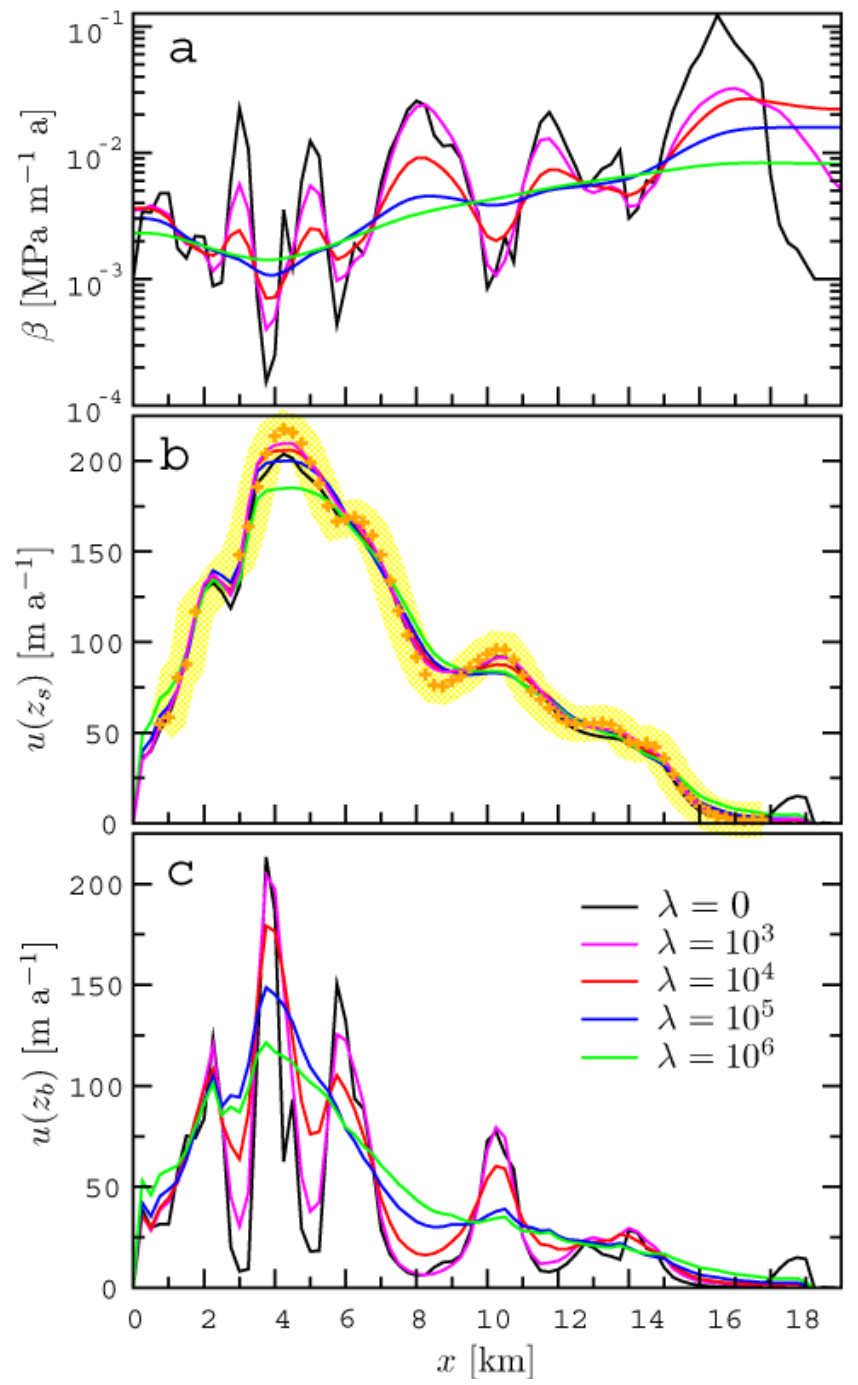

Fig. 2. Sensitivity of the results to the regularisation penalisation $\lambda$ for the 1978 summer data. (a) Distribution of the inferred basal friction parameter $\beta$ along the central flow line and corresponding (b) modelled and measured (orange cross) surface velocities and (c) modelled basal velocities. The yellow band represents the $\pm 10 \mathrm{~m} \mathrm{a}^{-1}$ error on the velocity measurements estimated by Raymond and Harrison (1988).

obtained L-curve is not even a strictly decreasing function as expected theoretically (when $\lambda$ increases from 0 to $10^{3}, J_{o}$ decreases). This might be explained by the fact that the gradient of the cost function in the Arthern and Gudmundsson (2010) method is only an approximation for the non-linear rheology, so that the exact minimum of the cost function may not be reached exactly for any $\lambda$. Nevertheless, from this Lcurve, one can expect the optimal $\lambda$ to be larger than $10^{3}$ and adding the previous analysis on the velocity accuracy, one might conclude that the optimal $\lambda$ lies in between $10^{3}$ and $10^{5}$. As can be seen in Fig. 2 , the $\beta$ distributions obtained for this range of regularisation parameters are still very distant.

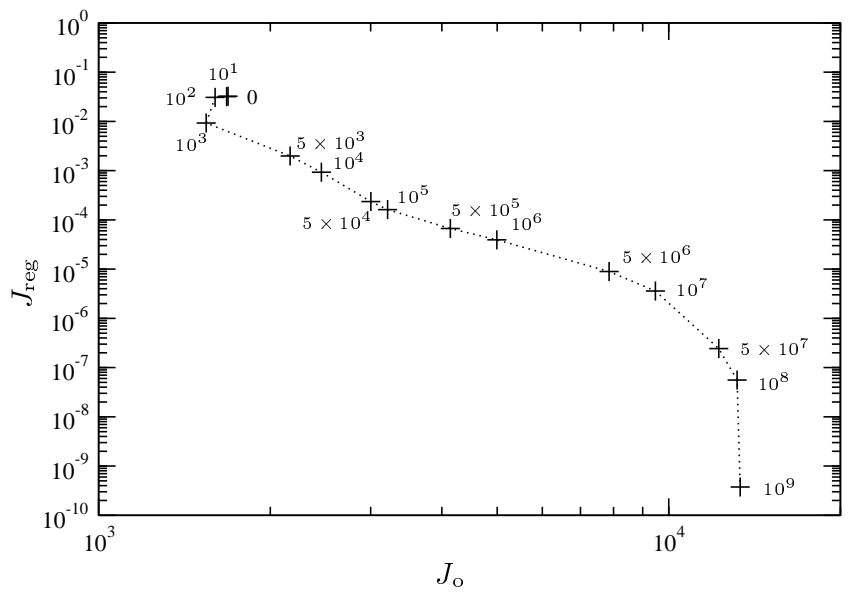

Fig. 3. Log-log plot of the norm of the regularised solution $J_{\text {reg }}$ given by Eq. (13) versus the norm of the initial cost function $J_{O}$ given by Eq. (9), the so-called L-curve. The cross correspond to the regularisation parameters from $\lambda=0$ up to $\lambda=10^{9}$.

Because the objective of this paper is to study changes in basal conditions over a $10-y r$ period, we will arbitrarily choose the smoothest solution and adopt in what follow a regularisation parameter $\lambda=10^{5}$. Spatial variation of the friction parameter along the flow line will therefore only be discussed if they arise over long distance, and we will concentrate the results analysis on the mean evolution of $\beta$ over the 10-yr dataset.

Note that the L-curve analysis should be conducted for all dataset and might conduct to different values of the regularisation parameter despite the weighting by $\bar{u}^{\text {obs }}$ of the regularisation term in Eq. (14). Because this analysis would necessitate a large number of simulations, it was not reasonably feasible for the 25 datasets, and in what follow, the value $\lambda=10^{5}$ is then adopted for all the datasets.

\subsection{Inferred basal friction parameter distributions}

The distribution of the friction parameter was inferred using the same method for the 25 datasets available during the quiescent phase and the surge. Results are shown in Fig. 4. Seasonal changes between summer and winter can be observed. For a given year, the winter always presents higher friction than the previous summer. But, during the eight years of the quiescent phase, the friction parameter $\beta$ regularly decreases, so that the last winter values are smaller than the first summer ones. Another remarkable feature is that the friction decrease is more pronounced in the upper part of the glacier than in the lower part during the quiescent phase. Contradictory to the assumption made by Bindschadler (1982), our results indicate that sliding already contributes for a large part of the total motion of the glacier during the quiescent phase. As shown in Fig. 5, the contribution of the basal velocity continuously increases during the quiescent phase, 


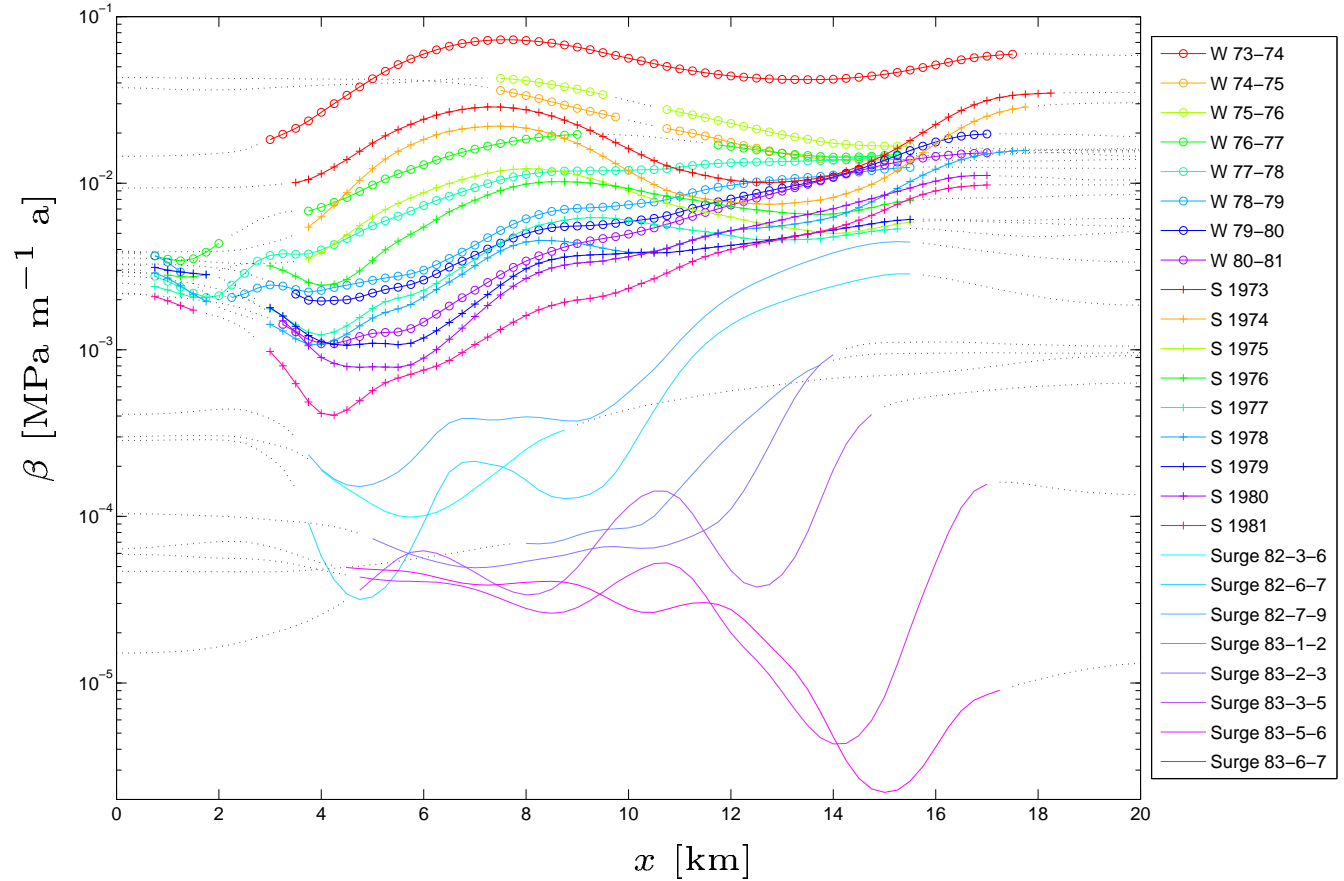

Fig. 4. Distribution of the basal friction parameter $\beta$ along the central flow line for the 25 dates of measurements. Dotted curves indicate where measured surface velocities are missing. In the legend, W Y1-Y2 denotes the mean velocity for the winter from year Y1 to year Y2, S Y denotes the mean velocity for the summer of year Y and Surge Y-M1-M2 the mean velocity for year Y from month M1 to month M2.

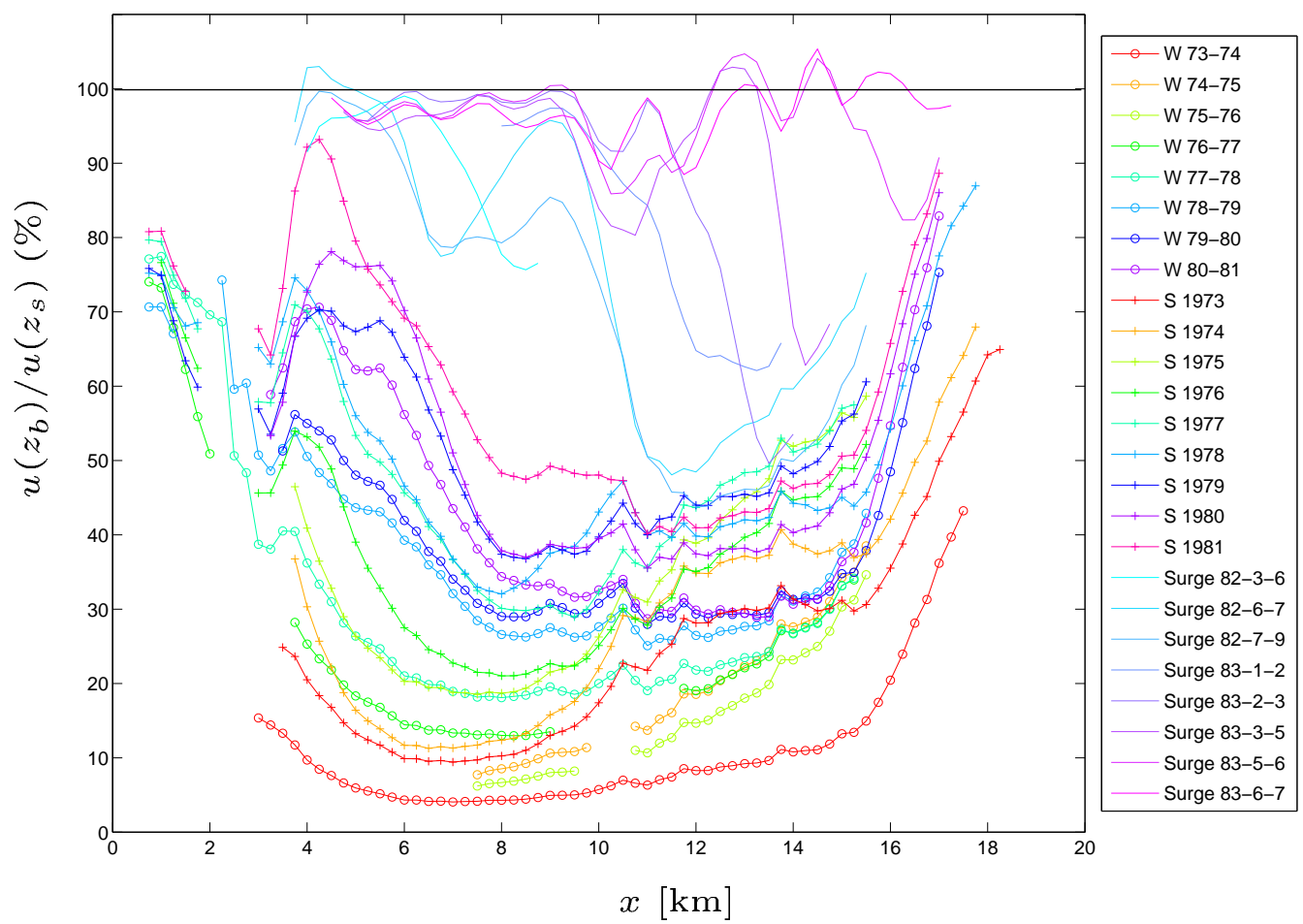

Fig. 5. Distribution of the ratio of the modelled horizontal basal velocity $u\left(z_{\mathrm{b}}\right)$ over the surface velocity $u\left(z_{\mathrm{s}}\right)$ along the central flow line for the 25 dates of measurements. Results are shown only where velocity has been measured. For the legend, see caption of Fig. 4 
from a mean value of $10 \%$ in winter 1973 up to $60 \%$ for summer 1981 just before the surge started, confirming the values inferred by Raymond and Harrison (1988) using a simple model. Such progressive increase of the basal sliding during the quiescent phase might confirm, as suggested for slow-type surging glaciers by Frappé and Clarke (2007) for Trapridge glacier and Sund et al. (2009) for Svalbard glaciers, that even for a fast-type surging glacier like Variegated, the surge phase is in fact the final phase of a progressive acceleration.

Nevertheless, at the onset of the surge in winter 19811982, dramatic changes in the basal friction occur, principally in the upper part of the glacier. The inferred friction parameter drops by about one order of magnitude from $10^{-3}$ to $10^{-4} \mathrm{MPa} \mathrm{m}^{-1} \mathrm{a}$, causing a high increase of the basal sliding, as shown in Figs. 4 and 5. Therefore, even if basal sliding regularly increases during the quiescent phase, initiation of Variegated surge is clearly marked by a jump in its basal conditions, leading to a clear distinction between the quiescent and surge phases. After this onset phase, the friction continues to decrease regularly until the end of the surge in July 1983. Both phases of the surge are visible in the results. The first phase occurs only in the upper part of the glacier from March 1982 to September 1982 and ends with a punctual increase of the basal friction. The second phase starts in January 1983 and spreads down the glacier until July 1983 with a dramatic decrease of the basal friction. During the second part of the surge, we observe the propagation of a low basal friction area from the middle part of the glacier down to its terminus. At the end of the simulated surge, the basal sliding accounts for more than $90 \%$ of the observed surface velocities everywhere on the glacier, whereas it is only the case in the upper part during the first phase of the surge. Figure 5 shows that at some places along the flow line, basal velocities are even greater than the surface ones. This is possible because of the stress transmission when solving the Stokes system with no simplification.

The inversion procedure gives a good representation of the observed velocities of each date of the 10-yr dataset. The observed changes in surface velocities during the quiescent and surge phases can be explained by changes in the basal sliding velocity and thus are clearly visible in the inferred distributions of the friction parameter $\beta$. Here, the simplest linear friction law (Eq. 7) is assumed, in which the friction parameter $\beta$ encompasses all the complexity of basal friction. In the next section, following the idea proposed by Flowers et al. (2011), the inferred friction parameter distribution $\beta\left(x_{i}, t_{j}\right)$ ( $i=1,81$ points and $j=1,25$ dates) is interpreted in terms of changes of the effective pressure at the base of Variegated Glacier from 1973 to 1983 , using a more complex friction law.

\section{Basal water distributions}

\subsection{A water-dependent friction law}

Many authors have attempted to infer from physical and mathematical considerations which variables should be incorporated in a realistic friction law (e.g. Weertman, 1957; Lliboutry, 1968, 1979; Nye, 1969, 1970; Kamb, 1970, 1987; Morland, 1984; Fowler, 1981, 1986, 1987; Gudmundsson, 1997a,b; Schoof, 2005). Schoof (2005) from mathematical developments, and Gagliardini et al. (2007) from finite element simulations have both proposed a similar friction law for the flow of clean ice over a rigid bedrock in presence of cavitation. In its simplest form, where the basal drag tends asymptotically to its maximum value (post-peak exponent $q=1$ in Gagliardini et al., 2007), this friction law is of the form:

$\frac{\tau_{n t}}{N}=C\left(\frac{u_{t}^{(1-n)}}{C^{n} N^{n} A_{\mathrm{s}}+u_{t}}\right)^{1 / n} u_{t}$.

In the above equation, $A_{\mathrm{s}}$ is the sliding parameter in the absence of cavitation and $n$ Glen's law exponent, resulting in a non-linear relation between the basal drag $\tau_{n t}$ and the basal sliding velocity $u_{t}$. Note that in the limit case where $n=1$ and $N \gg 0$, the sliding parameter $A_{\mathrm{s}}$ and the friction parameter $\beta$ are inversely proportional. As shown by Schoof (2005), the coefficient $C$ is lower than the maximum local positive slope of the bedrock topography at a decimetre to meter scale, so that the ratio $\tau_{n t} / N \leq C$ fulfils Iken's bound (Iken, 1981). The friction law (15) is strongly related to the water pressure $p_{\mathrm{w}}$ through the effective pressure $N=-\sigma_{n n}-p_{\mathrm{w}}$. When $p_{\mathrm{w}}=0$, the effective pressure is equal to the normal compressive Cauchy stress, and increasing water pressure leads to a decrease of $N$ toward zero. The two parameters $A_{\mathrm{s}}=A_{\mathrm{s}}(x)$ and $C=C(x)$ are only a function of space whereas the time-dependent changes are due to changes in the effective pressure $N=N(x, t)$. Note that effective pressure changes reflect changes in water pressure and/or basal normal stress, as discussed below.

Assuming $A_{\mathrm{s}}$ and $C$ are known, the effective pressure, and thus the water pressure, can be evaluated from the previous inversion results for all points $x_{i}$ and all dates $t_{j}$, as follows:

$N\left(x_{i}, t_{j}\right)=\frac{\beta u_{t}}{C\left(1-\beta^{n} u_{t}^{(n-1)} A_{\mathrm{s}}\right)^{1 / n}}$,

and then $p_{\mathrm{w}}=-N-\sigma_{n n}$.

Physically, the effective pressure is bounded, i.e. $0<$ $\tau_{n t} / C \leq N \leq-\sigma_{n n}$, but the evaluation of $N\left(x_{i}, t_{j}\right)$ from Eq. (16) can be out of these bounds due to the assumed $A_{\mathrm{s}}$ and $C$ distributions. The upper bound $N \leq-\sigma_{n n}$ (or $p_{\mathrm{w}} \geq 0$ ) is violated where the sliding parameter $A_{\mathrm{s}}$ is too high, so that even with zero water pressure the sliding velocity is too large. The bound $N \geq \tau_{n t} / C$ (or $p_{\mathrm{w}} \leq-\sigma_{n n}-\tau_{n t} / C$, reminding 
$\sigma_{n n}<0$ and $\tau_{n t}>0$ ) is never violated since it corresponds to infinitely great sliding velocity.

By considering the upper bound, it is possible to estimate the sliding parameter in absence of cavitation $A_{\mathrm{s}}$ so that $N \leq$ $-\sigma_{n n}$ is always fulfilled. Assuming zero water pressure $(N=$ $\left.-\sigma_{n n}\right)$, the sliding parameter reduces to

$A_{\mathrm{s}}=\frac{u_{t}^{(1-n)}}{\beta^{n}}-\frac{u_{t}}{C^{n}\left(-\sigma_{n n}\right)^{n}}=u_{t}\left(\frac{1}{\tau_{n t}^{n}}-\frac{1}{C^{n}\left(-\sigma_{n n}\right)^{n}}\right)$.

Because $\tau_{n t} \ll \sigma_{n n}, A_{\mathrm{s}} \approx u_{t} / \tau_{n t}^{n}$ and it implies that $A_{\mathrm{s}}$ is almost independent of the choice $C$. Therefore, from Eq. (16), one can conclude that the effective pressure is simply inversely proportional to $C$.

The distribution of the minimal sliding parameter $A_{\mathrm{s}}^{\min }$ is then evaluated from Eqs. (7) and (17), such that:

$A_{\mathrm{s}}^{\min }\left(x_{i}\right)=\min _{t_{j}}\left(A_{\mathrm{S}}\left(x_{i}, t_{j}\right)\right)=\min _{t_{j}}\left(\frac{u_{t}^{(1-n)}}{\beta^{n}}-\frac{u_{t}}{C^{n}\left(-\sigma_{n n}\right)^{n}}\right)$,

where $\beta, \sigma_{n n}$ and $u_{t}$ are defined at each date $t_{j}$ and each point $x_{i}$ where data are available. It is found that the minimal value of $A_{\mathrm{s}}$ inferred from Eq. (18) is everywhere obtained for the winter 1973 dataset, except for the upper and lower points for which no measurement was performed in 1973. This indicates that basal sliding during winter 1973 represents the lowest values of the following 10 -yr period.

In what follow, in absence of bedrock roughness data, we will hereafter assume a uniform $C$ distribution $(C=0.5)$. The sliding parameter in absence of cavitation $A_{\mathrm{s}}$ is determined then from Eq. (18). As already mentioned, because of this arbitrary choice of the value of the $C$ parameter, the inferred water pressures should not be regarded as actual values and only relative changes will be discussed.

\subsection{Modelled change in basal water pressure}

Using the inferred sliding parameter distribution $A_{\mathrm{s}}^{\min }(x)$, the water pressure for the 25 dates is then obtained from Eq. (16). Figure 6 shows the evolution with time (vertical axis) and space (horizontal axis) of the ratio of the water pressure over the normal stress $-p_{\mathrm{w}} / \sigma_{n n}$. This ratio is plotted instead of the effective pressure $N$ because it is visually easy to interpret. When this ratio tends toward 1 , the effective pressure tends toward zero and the sliding is increased.

The most noticeable result is that the large changes in the friction parameter $\beta$ shown in Fig. 4 are associated with relatively small changes in terms of water pressure. As shown in Fig. 7, the basal normal stress is almost constant during the 10 -yr period, despite strong variations along the flow line. Therefore, changes with time of the ratio $-p_{\mathrm{w}} / \sigma_{n n}$ are mostly due to changes in water pressure. As shown in Fig. 6 , the ratio $-p_{\mathrm{w}} / \sigma_{n n}$ only evolves between 0.7 to 1 , if we except the winter 1973 for which it is zero due to the definition of the $A_{\mathrm{s}}$ parameter. This strong non-linear response between basal drag and water pressure can be explained by the shape of the friction law used here and the fact that it is bounded for large sliding velocity (see Fig. 8 in Gagliardini et al., 2007). For low sliding velocity corresponding to great effective pressure, a great increase in water pressure is needed to increase the velocity. For great sliding velocity, it is the opposite due to the asymptotical behaviour of the friction law, and a small increase in water pressure leads to great increase in velocity.

Again, the seasonality of the sliding, as well as the two phases of the surge, are visible in the water pressure, as depicted in Fig. 6. Also, as was already inferred from the $\beta$ inversion, the greatest changes are observed in the upper part of the glacier during the quiescent phase and the first surge phase. For the second phase of the surge, we observe the propagation of a high water pressure area from the upper part to the lower part of the glacier, while the pressure in the upper part still remains significant. During this last stage, the increase of water pressure, even though relatively small (2$6 \%$ ), leads to very large increase of the ice flow.

Finally, note, that even if the normal stress $\sigma_{n n}$ is almost constant, a slight and progressive increase of $\sigma_{n n}$ in the upper part of the glacier is visible in the years before the surge, induced by an increase of the observed ice thickness. During the surge, this increase propagates down the glacier attesting displacement of the ice mass.

\subsection{Effect of basal topography on basal water pressure}

The topography clearly affects the water pressure below Variegated Glacier. First, each bump in the bedrock induces a higher normal stress $\sigma_{n n}$ on its upstream face (Fig. 7). Surprisingly, it is also the places where the ratio $-p_{\mathrm{w}} / \sigma_{n n}$ increases, indicating that these are the areas where the increase of the water pressure is the highest. These bedrock bumps, and more particularly the one located at $x=10 \mathrm{~km}$, seem to restrain the water in an upstream catchment. This interpretation is consistent with the surge hypothesis formulated by Lingle and Fatland (2003). Indeed, the progressive evolution of the surface topography of Variegated Glacier leads to an increasingly constricted water catchment upstream $x=10 \mathrm{~km}$, which increases slightly the water pressure up to a threshold value for which the surge occurs. As shown in Fig. 6, a high water pressure area of approximately $2 \mathrm{~km}$ is present since the beginning of the measurement period, but one can observe an increase with time of the water pressure upstream this area, indicating an upstream growth of the water catchment. The first phase of the surge is characterised by a sudden increase of the water pressure in the whole upper glacier upstream $x=10 \mathrm{~km}$. During the second phase of the surge, the propagation of the high water pressure area downstream $x=10 \mathrm{~km}$ (Fig. 6) is probably a consequence of the destruction of the water catchment during the first surge stage, leading to the opening of the initially constricted water catchment. 


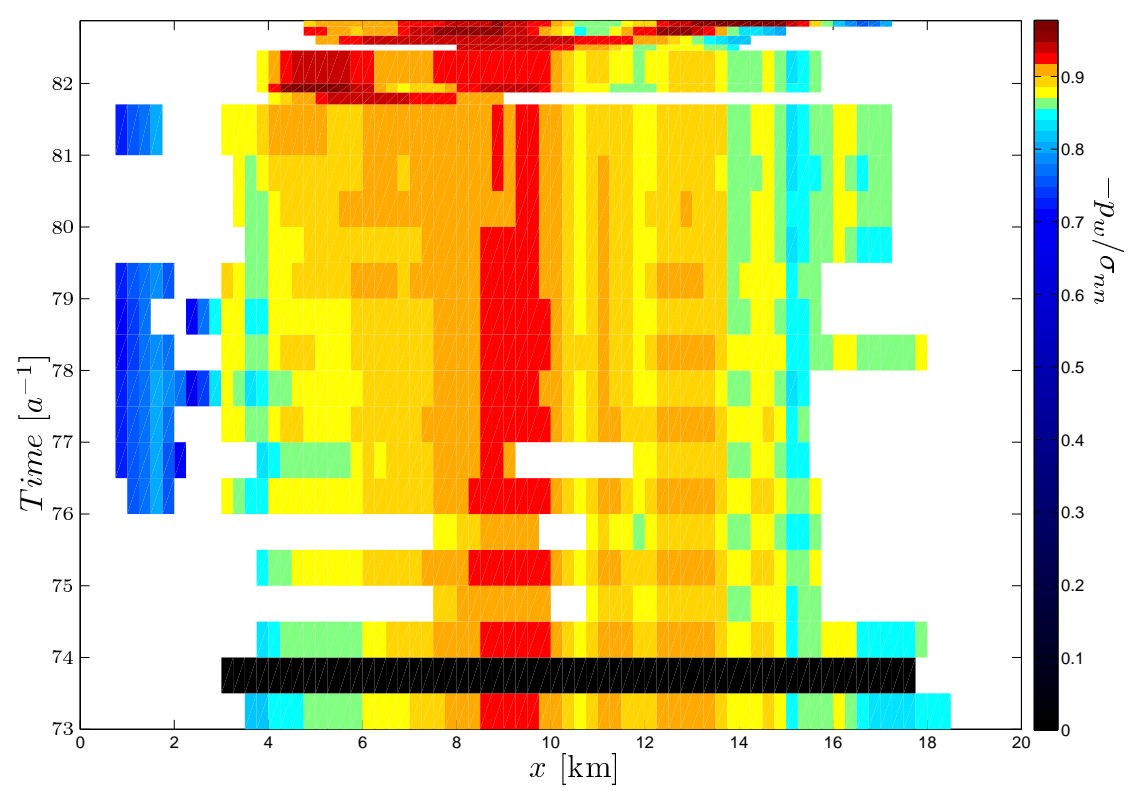

Fig. 6. Evolution with time since 1973 (vertical axis) and position along the central flow line (horizontal axis) of the ratio of basal water pressure over basal normal stress $-p_{\mathrm{w}} / \sigma_{n n}$.

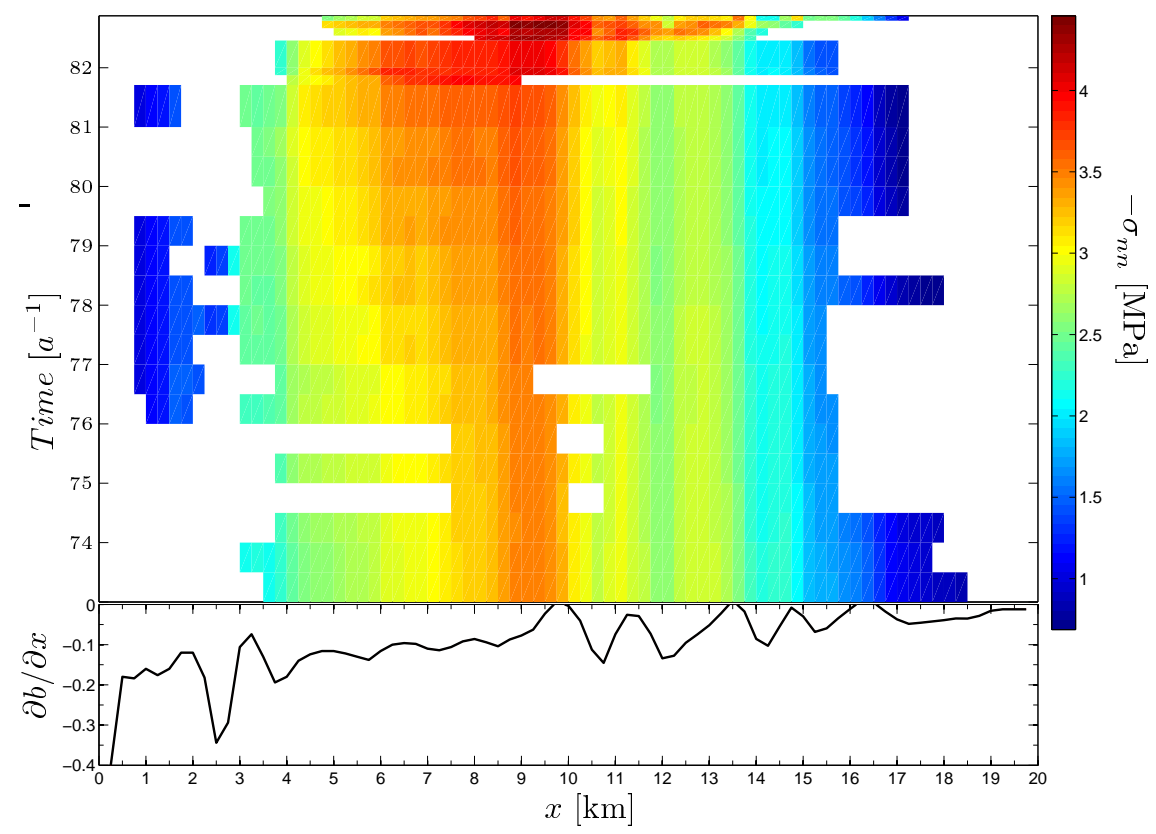

Fig. 7. Evolution with time since 1973 (vertical axis) and position along the central flow line (horizontal axis) of the modelled basal normal stress $-\sigma_{n n}[\mathrm{MPa}]$. The lower panel represents the bedrock slope $\partial b / \partial x$.

\section{Direct prognostic simulations}

From the previous analysis, the friction parameter $\beta$ is reconstructed for the 25 datasets from summers 1973 to 1983. To test the sensitivity of the model to the surface geometry, we run a prognostic time-dependent simulation assuming a constant mass balance over these $10 \mathrm{yr}$ and the previously inferred history of the friction parameter.
Starting from the summer 1973 surface geometry, the upper free surface is evolved using the following kinematic boundary condition:

$\frac{\partial z_{\mathrm{s}}}{\partial t}+u_{x} \frac{\partial z_{\mathrm{s}}}{\partial x}-u_{z}=a_{s}$,

where $a_{s}$ is the accumulation/ablation function. This function is estimated from the average mass balance measured 


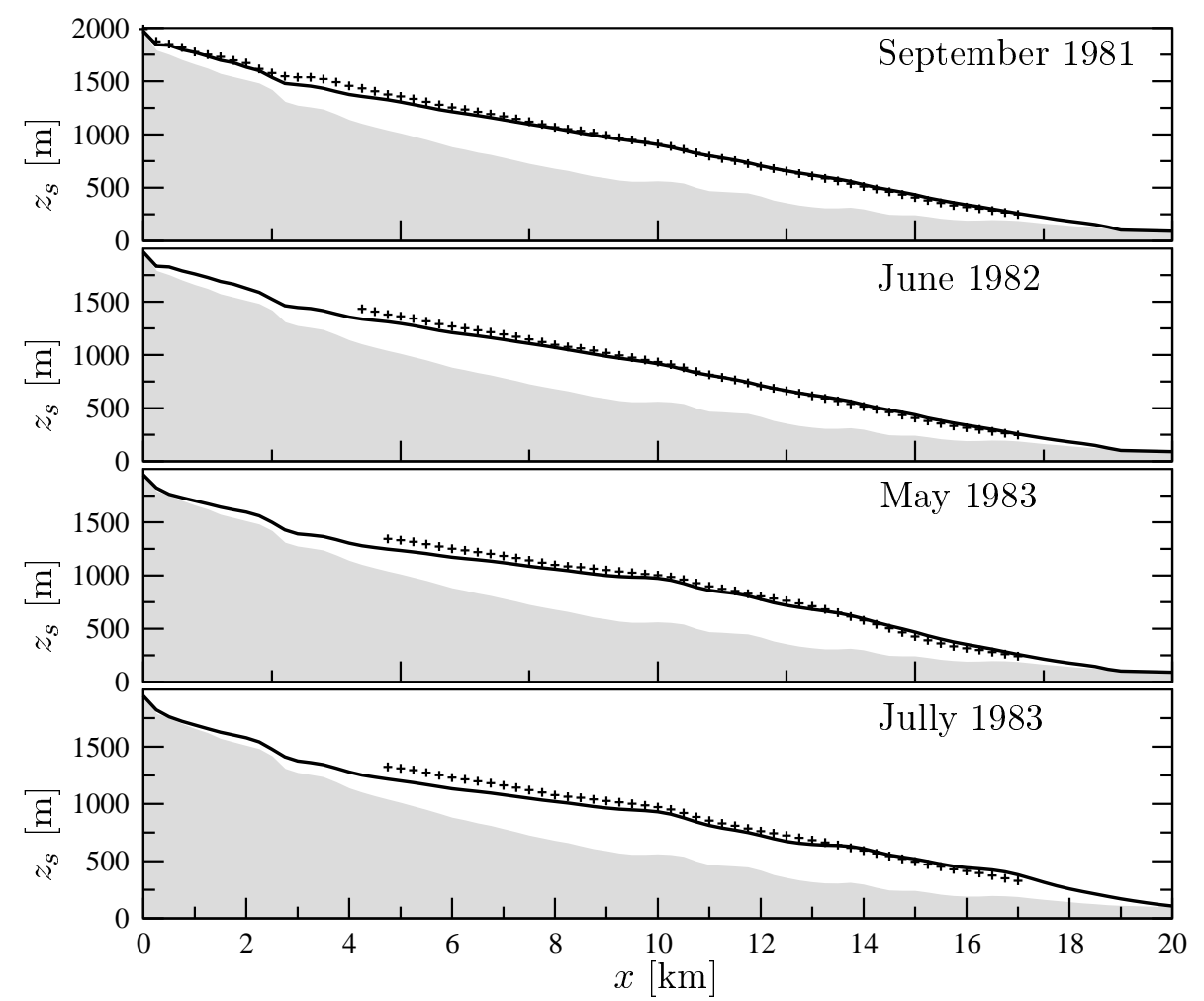

Fig. 8. Comparison of modelled (line) and measured (cross) surface geometries at four different dates.

on Variegated Glacier between 1972 to 1976 (Bindschadler, 1982). The mass balance (in $\mathrm{ma}^{-1}$ ) is supposed to be linearly dependent on the surface altitude $z_{\mathrm{S}}$ (in $\mathrm{m}$ ) and the equilibrium line located at $1050 \mathrm{~m}$ a.s.l., such that:

$a_{s}=\min \left(6 \frac{z_{\mathrm{s}}-1050}{885} ; 3.2\right)$.

The Stokes Eqs. (1) and (2) using the basal boundary condition (Eq. 7), and the free surface evolution Eq. (19) are coupled and solved iteratively using a time step of $0.1 \mathrm{a}$. At each time step, the basal friction parameter $\beta$ is interpolated linearly from the two closest datasets in the time-series.

The modelled surface is compared with the observed surface at four different dates just before, during and after the surge in Fig. 8. The modelled and observed surface elevations before and during the surge relative to the measured surface elevation of summer 1973 are shown in Figs. 9 and 10. Before the surge we observe a thickening of the upper part of the glacier and a thinning of the lower part. The timing and the magnitude of the changes are well reproduced by the model except on the highest part of the glacier where the model leads to a thinning of the glacier. Part of the discrepancies between the model and observations can be explained by errors in the mass balance and/or by three-dimensional effects (ice convergence along the central flow line, not accounted for in our model, Raymond, 1987). As a matter of fact, the Variegated volume has been observed to increase during the quiescent phase, whereas, in the model, the integrated mass balance is slightly negative leading to a decrease of the modelled ice volume. In Fig. 9, the oscillations of the elevation changes from 0 to $5 \mathrm{~km}$ are certainly explained by an initial surface being not in equilibrium with the model solution, because the convergence/divergence of the flow is not accounted for and the upper part of Variegated glacier is very steep.

As expected, the modelled surge occurs in phase with the observations when the friction parameter dramatically decreases in March 1982. The surge is characterised by a thinning of the upper part of the glacier and a thickening of the lower part which results in the advance of the ice front. As already observed for the quiescent phase, the upper part of the glacier is too thin when compared with summer 1973, but the timing of the mass transfer from the upper part to the lower part of the glacier is well captured by the model, and particularly the advance of the ice front position.

The ability of our model to reproduce the main characteristics of the surge justifies a posteriori the use of the diagnostic model to infer the basal friction distribution for each dataset independently. It demonstrates that the results are not very sensitive to the surface geometry and that the Robin inverse method (Arthern and Gudmundsson, 2010) with an appropriate regularisation allows us to retrieve a good order of magnitude of the friction parameter $\beta$ where surface velocity observations are available. The errors on the modelled topography 

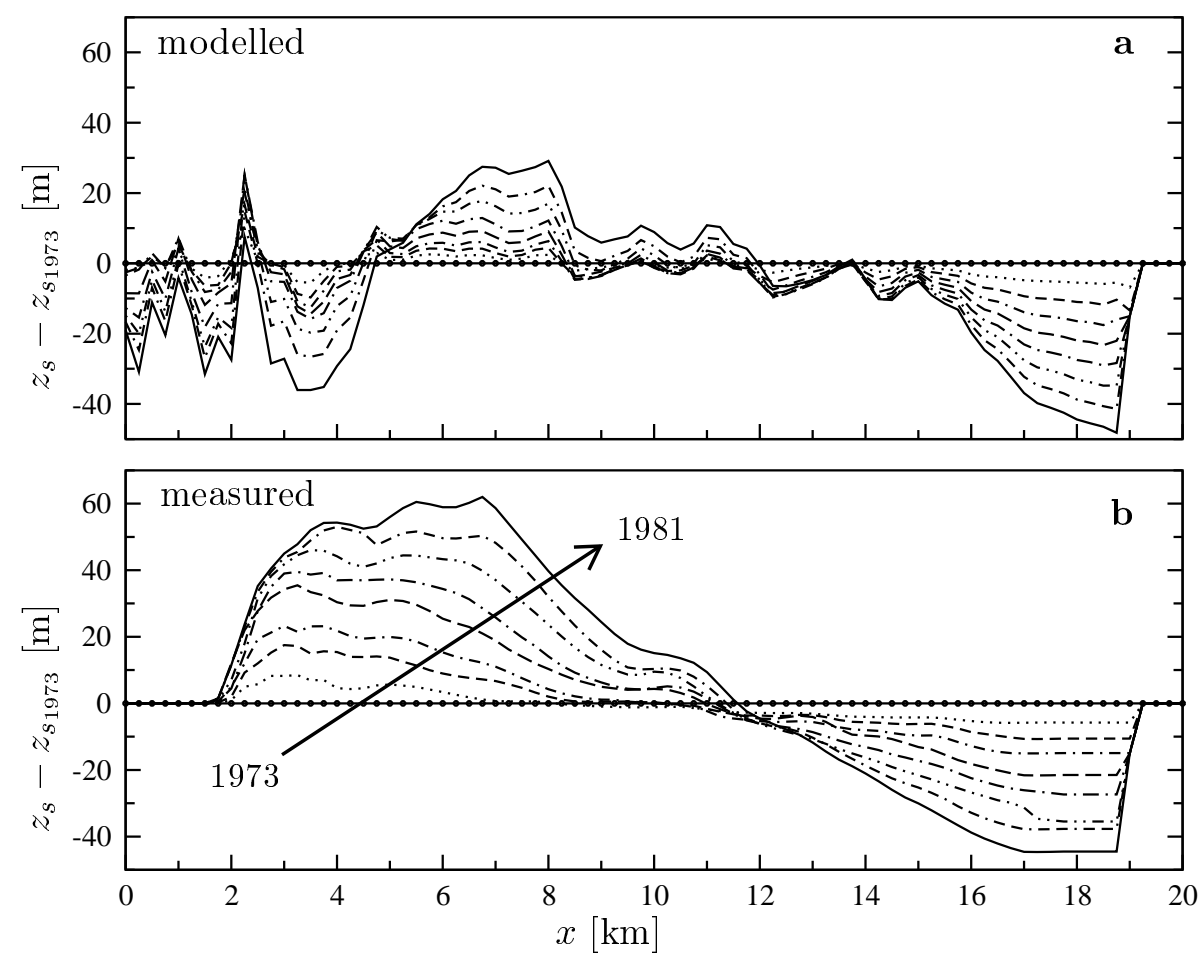

Fig. 9. Comparison of (a) modelled and (b) measured surface geometries relative to the 1973 surface topography for each date during the quiescent phase.
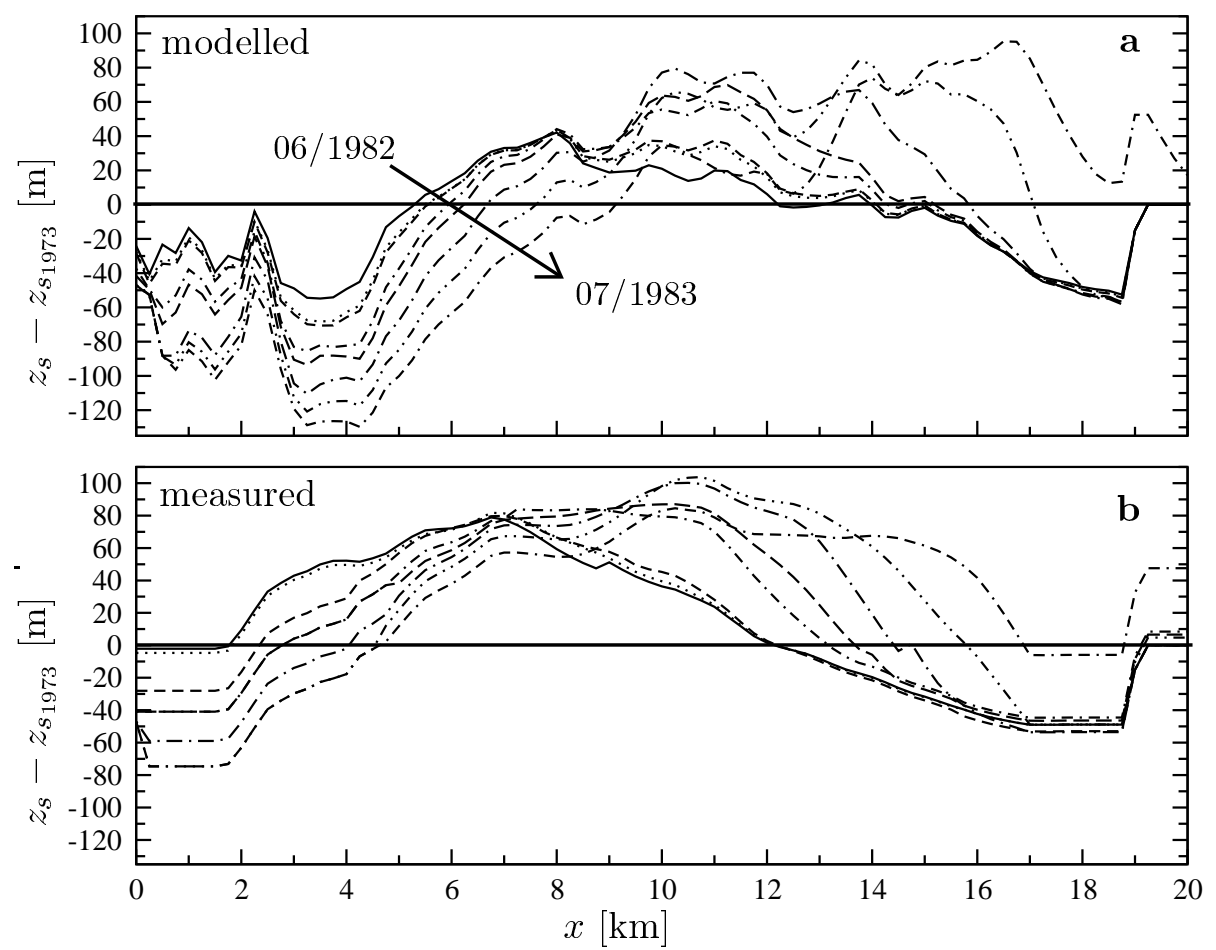

Fig. 10. Comparison of (a) modelled and (b) measured surface geometries relative to the 1973 surface topography for each date during the surge. 
can be likely explained by the lack of data (topography, velocities and mass balance) and three-dimensional effects.

\section{Conclusions}

We have presented the first application to a real case of the inverse method proposed by Arthern and Gudmundsson (2010). It demonstrates the strong relevance of this inverse method, which allowed the reconstruction of the basal conditions below Variegated Glacier along a $10-y r$ period consistent with surface elevation and velocity measurements. From this reconstruction of the friction parameter, water pressure changes were inferred using a water pressure dependent friction law. As an important result, we showed that very large changes in the basal friction parameter are induced by relatively small changes in basal water pressure. This is mainly due to the asymptotical behaviour of the friction law for great sliding velocity. Our results support the presence of a subglacial water storage in the mid-upper part of the glacier as proposed by Lingle and Fatland (2003).

To take this study further, our reconstruction of the basal water pressure changes over the 10 -yr period should be used to constrain a hydrological model coupled with an ice flow model, as in Pimentel et al. (2010). This would, however, need to be conducted using a three-dimensional modelling approach to overcome the limitations of a flow line hydrological model. This would be a significant step to fully relate the surge behaviour of Variegated Glacier to its surface mass balance over the decade 1973-1983.

Acknowledgements. This work was supported by both the ADAGe project (ANR-09-SYSC-001) funded by the Agence National de la Recherche (ANR) and the ice2sea project funded by the European Commission's 7th Framework Programme through grant number 226375 (ice2sea publication 32). Part of the computations presented in this paper were performed at the Service Commun de Calcul Intensif de l'Observatoire de Grenoble (SCCI). The authors thank C. Raymond who kindly helped us regarding the 1973-1983 dataset of Variegated Glacier. The authors thank the Scientific Editor G. H. Gudmundsson for suggesting the L-curve analysis to infer the optimal regularisation parameter. The authors are grateful for the pertinent comments from two anonymous referees which considerably improved our paper.

Edited by: G. H. Gudmundsson

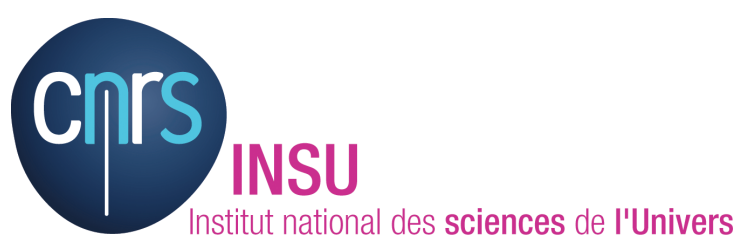

The publication of this article is financed by CNRS-INSU.

\section{References}

Arthern, R. and Gudmundsson, G.: Initialization of ice-sheet forecasts viewed as an inverse Robin problem, J. Glaciol., 56, 527533, 2010.

Bindschadler, R.: A Numerical Model of Temperate Glacier Flow Applied to the Quiescent Phase of a Surge-Type Glacier, J. Glaciol., 28, 239-265, 1982.

Bindschadler, R., Harrison, W. D., Raymond, C. F., and Crosson, R.: Geometry and dynamics of a surge-type glacier, J. Glaciol., 18, 181-194, 1977.

Cuffey, K. and Paterson, W. S. B.: The physics of glaciers, fourth edn., Pergamon, Oxford, 2010.

Eisen, O., Harrison, W. D., and Raymond, C. F.: The surges of Variegated Glacier, Alaska, USA, and their connection to climate and mass balance, J. Glaciol., 47, 351-358, 2001.

Eisen, O., Harrison, W., Raymond, C., Echelmeyer, K., Bender, G., and Gorda, J.: Variegated Glacier, Alaska, USA: a century of surges, J. Glaciol., 51, 399-406, 2005.

Flowers, G. E., Roux, N., Pimentel, S., and Schoof, C. G.: Present dynamics and future prognosis of a slowly surging glacier, The Cryosphere, 5, 299-313, doi:10.5194/tc-5-299-2011, 2011.

Fowler, A. C.: A theoretical treatment of the sliding of glaciers in the absence of cavitation, Philos. T. R. Soc. Lond., 298, 637-685, 1981.

Fowler, A. C.: A sliding law for glaciers of constant viscosity in the presence of subglacial cavitation, Proc. R. Soc. Lon. A, 407, 147-170, 1986.

Fowler, A. C.: Sliding with cavity formation, J. Glaciol., 33, 255267, 1987.

Frappé, T.-P. and Clarke, G. K. C.: Slow surge of Trapridge Glacier, Yukon Territory, Canada, J. Geophys. Res., 112, F03S32, doi:10.1029/2006JF000607, 2007.

Gagliardini, O. and Zwinger, T.: The ISMIP-HOM benchmark experiments performed using the Finite-Element code Elmer, The Cryosphere, 2, 67-76, doi:10.5194/tc-2-67-2008, 2008.

Gagliardini, O., Cohen, D., Råback, P., and Zwinger, T.: Finiteelement modeling of subglacial cavities and related friction law, J. Geophys. Res., 112, F02027, doi:10.1029/2006JF000576, 2007.

Gilbert, J.-C. and Lemaréchal, C.: Some numerical experiments with variable-storage quasi-Newton algorithms, Math. Program., 45, 407-435, 1989.

Goldberg, D. N. and Sergienko, O. V.: Data assimilation using a hybrid ice flow model, The Cryosphere, 5, 315-327, doi:10.5194/tc-5-315-2011, 2011.

Gudmundsson, G. H.: Basal-flow characteristics of a linear medium sliding frictionless over small bedrock undulations, J. Glaciol., 43, 71-79, 1997a.

Gudmundsson, G. H.: Basal-flow characteristics of a non-linear flow sliding frictionless over strongly undulating bedrock, J. Glaciol., 43, 80-89, 1997b.

Gudmundsson, G. H. and Raymond, M.: On the limit to resolution and information on basal properties obtainable from surface data on ice streams, The Cryosphere, 2, 167-178, doi:10.5194/tc-2167-2008, 2008.

Hansen, P.: The L-curve and its use in the numerical treatment of inverse problems, in: Computational inverse problems in electrocardiology, 5, 119-142, 2001.

Harrison, W. and Post, A.: How much do we really know about 
glacier surging?, Ann. Glaciol., 36, 1-6, 2003.

Harrison, W., Motyka, R., Truffer, M., Eisen, O., Moran, M., Raymond, C., Fahnestock, M., and Nolan, M.: Another surge of Variegated Glacier, Alaska, USA, 2003/04, J. Glaciol., 54(184), 192-194, 2008.

Iken, A.: The effect of the subglacial water pressure on the sliding velocity of a glacier in an idealized numerical model, J. Glaciol., 27, 407-421, 1981.

Kamb, B.: Sliding motion of glaciers: theory and observation, Rev. Geophys. Space Phys., 8, 673-728, 1970.

Kamb, B.: Glacier surge mechanism based on linked cavity configuration of the basal water conduit system, J. Geoph. Res., 92, 9083-9100, 1987.

Kamb, B., Raymond, C. F., Harrison, W. D., Engelhardt, H., Echelmeyer, K. A., Humphrey, N., Brugman, M. M., and Pfeffer, T.: Glacier surge mechanism: 1982-1983 surge of Variegated Glacier, Alaska, Science, 227, 469-479, 1985.

Lingle, C. and Fatland, D.: Does englacial water storage drive temperate glacier surges?, Ann. Glaciol., 36, 14-20, 2003.

Lliboutry, L.: General theory of subglacial cavitation and sliding of temperate glaciers, J. Glaciol., 7, 21-58, 1968.

Lliboutry, L.: Local friction laws for glaciers: a critical review and new openings, J. Glaciol., 23, 67-95, 1979.

Morland, L. W.: Glacier sliding down an inclined wavy bed, J. Glaciol., 17, 447-462, 1984.

Morlighem, M., Rignot, E., Seroussi, H., Larour, E., Dhia, H., and Aubry, D.: Spatial patterns of basal drag inferred using control methods from a full-Stokes and simpler models for Pine Island Glacier, West Antarctica, Geophys. Res. Lett., 37, L14502, doi:10.1029/2006JF000576, 2010.
Nye, J.: The flow of a glacier in a channel of rectangular, elliptic or parabolic cross-section, J. Glaciol., 5, 661-690, 1965.

Nye, J. F.: A calculation on the sliding of ice over a wavy surface using a Newtonian viscous approximation, Proc. R. Soc. Lon. A, 311, 445-467, 1969.

Nye, J. F.: Glacier sliding without cavitation in a linear viscous approximation, Proc. R. Soc. Lon. A, 315, 381-403, 1970.

Pimentel, S., Flowers, G., and Schoof, C.: A hydrologically coupled higher-order flow-band model of ice dynamics with a coulomb friction sliding law, J. Geophys. Res., 115, F04023, doi:10.1029/2009JF001621, 2010.

Raymond, C. F.: How Do Glaciers Surge? A Review, J. Geophys. Res., 92, 9121-9134, 1987.

Raymond, C. F. and Harrison, W. D.: Evolution of Variegated Glacier, Alaska, USA, prior to its surge, J. Glaciol., 34, 154-169, 1988.

Raymond Pralong, M. and Gudmundsson, G. H.: Bayesian estimation of basal conditions on Rutford Ice Stream, West Antarctica, from surface data, J. Glaciol., 57(202), 315-324, 2011.

Schoof, C.: The effect of cavitation on glacier sliding, Proc. R. Soc. Lon. A, 461, 609-627, 2005.

Sund, M., Eiken, T., Hgen, J. O., and Kääb, A.: Svalbard surge dynamics derived from geometric changes, Ann. Glaciol., 50(52), 50-60, 2009.

Weertman, J.: On the sliding of Glaciers, J. Glaciol., 3, 33-38, 1957. 